\title{
Pieniä kaalinkeriä vihannestiskeihin
}

\author{
Pirjo Kivijärvi ${ }^{1)}$ ja Veikko Hintikainen ${ }^{2)}$ \\ ${ }^{1)}$ MTT Mikkeli,Lönnrotinkatu 3, 50100 Mikkeli,pirjo.kivijarvi@mtt.fi \\ ${ }^{2)}$ MTT Mikkeli, Karilantie 2A, 50600 Mikkeli,veikko.hintikainen@mtt.fi
}

\section{Tiivistelmä}

Vuosina 2006 ja 2007 testattiin tilakokeissa kahdella eri tilalla useita valkokaalilajikkeita tavoitteena tuottaa pienikokoisia ja varastointia kestäviä keriä. Tavoitteeseen pyrittiin käyttämällä tiheämpää istutusta kuin normaalisti varastokaalin viljelyssä. Vuonna 2006 kokeet toteutettiin Mäntyharjussa EteläSavossa ja Pohjois-Pohjanmaalla Nivalassa, vuonna 2007 vain Nivalassa. Koealueiden viljelytoimenpiteet tehtiin tilojen viljelykäytäntöjen mukaan.

Kasvukaudella 2006 koelajikkeina olivat Guard, Topgun, Reaction, Budena ja Candela. Mäntyharjussa istutustiheys oli 38500 tainta/ha ja Nivalassa 45000 tainta/ha. Lajikekokeeseen liittyen tehtiin myös varastointikoe, jossa kustakin lajikkeesta varastoitiin kaksi kuution laatikkoa. Ensimmäinen erä kauppakunnostettiin tammikuussa ja toinen maaliskuussa 2007. Varastointikokeessa verrannelajikkeena oli tiloilla viljelyssä oleva ja meillä yleisin varastokaalilajike Lennox. Vuonna 2007 koelajikkeina olivat Attraction, Candela, Reaction, Kilaton, McCartney, Budena ja Paradox. Verrannelajikkeena oli Lennox. Paradox- ja Lennox-lajikkeiden istutustiheys oli 32000 tainta/ha, muiden lajikkeiden 38500 tainta/ha.

Vuonna 2006 parhaan kauppakelpoisen sadon Mäntyharjussa tuottivat Candela- ja Reactionlajikkeet, $68700 \mathrm{~kg} / \mathrm{ha}$ ja $67600 \mathrm{~kg} / \mathrm{ha}$. Nivalassa satoisimpia olivat Guard-, Reaction- ja Topgunlajikkeet, joiden kauppakelpoinen sato jäi hieman alle $60000 \mathrm{~kg} / \mathrm{ha}$. Lajikkeiden kauppakelpoisen sadon osuus oli yli 90 \% kokonaissadosta, paitsi Candela-lajikkeella Nivalassa. Vuonna 2007 verranteena ollut Lennox-lajikeen kauppakelpoinen sato oli lähes $63000 \mathrm{~kg} / \mathrm{ha}$. Koelajikkeista vain Attraction tuotti Lennoxia paremman kauppakelpoisen sadon, noin $70000 \mathrm{~kg} / \mathrm{ha}$. Lajikkeiden kokonaissadon kauppakelpoisuus oli Budena-lajiketta lukuun ottamatta yli $90 \%$.

Tiheällä istutuksella päästiin joillakin lajikkeilla haluttuun keräkokoon. Vuonna 2006 Nivalan kokeessa Budena- ja Candela-lajikkeiden kauppakelpoisesta sadosta pääosa oli tavoitellussa 0,75-1,5 kg:n kokoluokassa. Budena-lajike käyttäytyi Mäntyharjun kokeessa Nivalan kokeen tavoin. Muilla lajikkeilla pääosa kauppakelpoisesta sadosta oli kokoluokassa 1,5-2,5 kg. Vuonna 2007 ei tiheämmällä istutuksella saatu edellisen vuoden kaltaista vaikutusta kerien kokoon, johtuen ainakin osittain harvemmasta istutuksesta. Pienten kerien osuus sadosta jäi kaikilla lajikkeilla alle $30 \%$ :in.

Varastointikokeessa Topgun ja Budena säilyivät huonommin kuin muut lajikkeet. Parhaiten pitkässä varastoinnissa säilyivät Mäntyharjussa Candela-, Guard- ja Lennox-lajikkeet, joiden kauppakelpoisuus oli 75-77 \%. Nivalassa Guard-, Lennox- ja Reaction-lajikkeiden kauppakelpoisuus oli maaliskuun kauppakunnostuksessa vielä 82-86\%.

Asiasanat: lajike, valkokaali, varastointi, varastokestävyys 


\section{Johdanto}

Valko- eli keräkaalin tuotantoala on laskenut maassamme 1990-luvun puolivälistä vuoteen 2005 mennessä 975 hehtaarista 583 hehtaariin (Puutarhayritysrekisteri 2005). Tuona aikana vihannesten kokonaiskulutus on kuitenkin ollut tasaisessa nousussa, joten valkokaalia on korvattu muilla vihanneksilla. Valkokaali ei tällä hetkellä ole muodissa ruoan valmistuksessa, vaikka se on terveellinen, vähäkalorinen ja hinnaltaan edullinen lämpimien ruokien, salaattien ja säilykkeiden raaka-aine.

Yksi syy valkokaalin kulutuksen alamäkeen voi olla varsinkin talvikaudella kauppojen vihannestiskeissä tarjolla olevat isot kerät. Kaupat yrittävät ratkaista ongelmaa halkomalla keriä kahteen tai jopa neljään osaan. Tällöin kerien leikkauspinnat tummuvat ja lähtevät pilaantumaan, mikä vähentää kaalien houkuttelevuutta ostopäätöksiä tehtäessä. Viljelijällä saattaa hyvinkin olla mielenkiintoa kasvattaa isoja keriä ja paljon kiloja, jolloin sadonkorjuussa ja varastosta kauppakunnostuksessa säästää työtä. Isot kerät kuuluvat kuitenkin suurkeittiö- tai kaalieinesten raaka-aineeksi. Kauppojen vihannestiskeissä tulisi kuluttajalle tarjota 1-1,5 kg:n painoisia keriä. Kasvukausina 2006-2007 toteutetuissa tilakokeissa tavoitteena oli tuottaa pieniä ja varastointia kestäviä keriä. Kerien kasvua pyrittiin rajoittamaan normaalia tiheämmällä istutuksella.

\section{Aineisto ja menetelmät}

Vuonna 2006 kaalilajikkeiden testaus toteutettiin tilakokeina kahdessa eri hankkeessa, MTT Mikkelin koordinoimassa Etelä-Savon vihannestuotannon kehittäminen-hankkeessa ja Oulun yliopiston hallinnoimassa Lähiruokaa markkinoille -hankkeessa. Kokeet perustettiin Mäntyharjulle ja Nivalaan. Testatut lajikkeet olivat Guard, Topgun, Reaction, Budena ja Candela. Mäntyharjussa koe istutettiin 20.5.2006 taimimäärällä $38500 \mathrm{kpl} / \mathrm{ha}$. Koealueiden sato korjattiin 27.9 ja 4.10. Nivalassa koetaimet istutettiin 23.5.2006 taimimäärällä $45000 \mathrm{kpl} / \mathrm{ha}$ ja koealueiden sato korjattiin 2.10. Lajikekokeeseen kuului myös varastointikoe, jossa kutakin lajiketta nostettiin varastoon kaksi kuution laatikkoa. Varastointikokeessa verrannelajikkeeksi otettiin tiloilla viljelyssä oleva varastokaalilajike Lennox, joka oli kasvanut pellolla lajikkeelle tyypillisessä istutustiheydessä, 28000 tainta/ha. Ensimmäinen erä $\left(1 \mathrm{~m}^{3}: \mathrm{n}\right.$ laatikko/lajike) kauppakunnostettiin tammikuun lopussa ja toinen maaliskuun lopussa 2007. Ensimmäisen kauppakunnostuksen yhteydessä määritettiin kunkin lajikkeen kerän keskipaino jakamalla kolmen tukkupakkauksen (3 x $20 \mathrm{~kg}$ ) yhteispaino pakkauksissa olleiden kaalien lukumäärällä.

Vuonna 2007 tilakoe toteutettiin vain Nivalassa. Koelajikkeina olivat Attraction, Candela, Reaction, Kilaton, McCartney, Budena ja Paradox. Verrannelajikkeena oli Lennox. Paradox- ja Lennoxlajikkeiden istutustiheys oli 32000 tainta/ha, muiden lajikkeiden 38500 tainta/ha. Lajikkeet istutettiin 22.5. ja sato korjattiin 2.10. Molempina koevuosina taimien kasvatus, taimien istutus ja koealueiden hoito tehtiin tilojen viljelykäytäntöjen mukaan.

Lajikkeiden sato määritettiin kolmelta näytealalta/koelajike. Yhdeltä näytealalta nostettiin 20 kerää. Näytealojen sato luokiteltiin kauppakelpoisiin ja ei-kauppakelpoisiin. Kauppakelpoinen sato jaettiin kerän koon mukaan kokoluokkiin 0,75-1,5 kg, 1,5-2,5 kg ja yli 2,5 kg. Ei-kauppakelpoinen sato luokiteltiin seuraavasti: alle $0,75 \mathrm{~kg}: n$ kerät, tautien pilaamat ja tuholaisten vioittamat. Kerien lukumäärä laskettiin ja sato punnittiin kaikissa lajitteluluokissa. Tämän jälkeen jokaisen koealan kauppakelpoisista keristä valittiin seitsemän kerää, jotka halkaistiin ja arvioitiin seuraavasti: kerän korkeus $(\mathrm{cm})$, kannan korkeus $(\mathrm{cm})$, väri 1-5 (1=vaalen vihreä, 5=tumman vihreä), muoto $1-5$, (1=litteälitteänpyöreä, $\quad 2$ =pyöreä-pitkänpyöreä, 3 =suippokärkinen-suippokärkisen pyöreä, $\quad 4=$ soikeavastapuikea ("ilmapallomainen"), 5= litteän vastapuikea) ja kiinteys 1-5 (1=löyhä, 5=tiivis). Satotulokset on laskettu kolmen koealueen keskiarvoina.

\section{Tulokset ja tulosten tarkastelu}

Vuonna 2006 paras kauppakelpoinen sato Mäntyharjussa saatiin Reaction- ja Candela-lajikkeista, kun taas Nivalassa Guard, Topgun ja Reaction olivat hyvin tasavahvoja. Budena-lajikkeelle on ominaista pienikasvuisuus, mikä jonkin verran pienensi sen satomäärää. Nivalassa Candela-lajikkeen sato jäi muihin lajikkeisiin verrattuna yllättävän alhaiseksi. Yhtenä syynä alhaiseen satoon oli alle kauppakelpoisuusrajan olevien pienien kerien suhteellisen suuri osuus sadossa. Lajikkeiden kauppakelpoisen 
sadon osuus oli yli 90 prosenttia kokonaissadosta. Poikkeuksena oli Nivalan kokeen Candela-lajike, jonka sadon kauppakelpoisuus jäi 83 prosenttiin (Taulukko 1.).

Taulukko1. Varastokeräkaalin koelajikkeiden kauppakelpoinen sato (kg/ha) ja kauppakelpoisuus-\% kokonaissadosta Mäntyharjun ja Nivalan kokeissa vuonna 2006.

\begin{tabular}{llllll}
\hline & \multicolumn{4}{c}{ Kauppakelpoinen sato } \\
\cline { 2 - 3 } \cline { 2 - 3 } \cline { 5 - 6 } Lajike & \multicolumn{2}{c}{ Mäntyharju } & & \multicolumn{2}{c}{ Nivala } \\
\cline { 2 - 3 } Candela & 68654 & 97 & & 38447 & 83 \\
Reaction & 67603 & 99 & & 58295 & 92 \\
Topgun & 58103 & 96 & & 59318 & 92 \\
Guard & 55827 & 96 & & 57258 & 93 \\
Budena & 49558 & 97 & & 48523 & 94 \\
\hline
\end{tabular}

Normaalia tiheämmällä istutuksella päästiin joillakin lajikkeilla tavoiteltuun keräkokoon. Mäntyharjun kokeessa Budena-lajike tuotti pääosin pieniä keriä. Nivalassa Budena- ja Candela-lajikkeilla pääosa kauppakelpoisesta sadosta oli 0,75-1,5 kg:n kokoluokassa, muilla lajikkeilla kokoluokassa 1,5-2,5 kg (Kuvat 1. ja 2.).

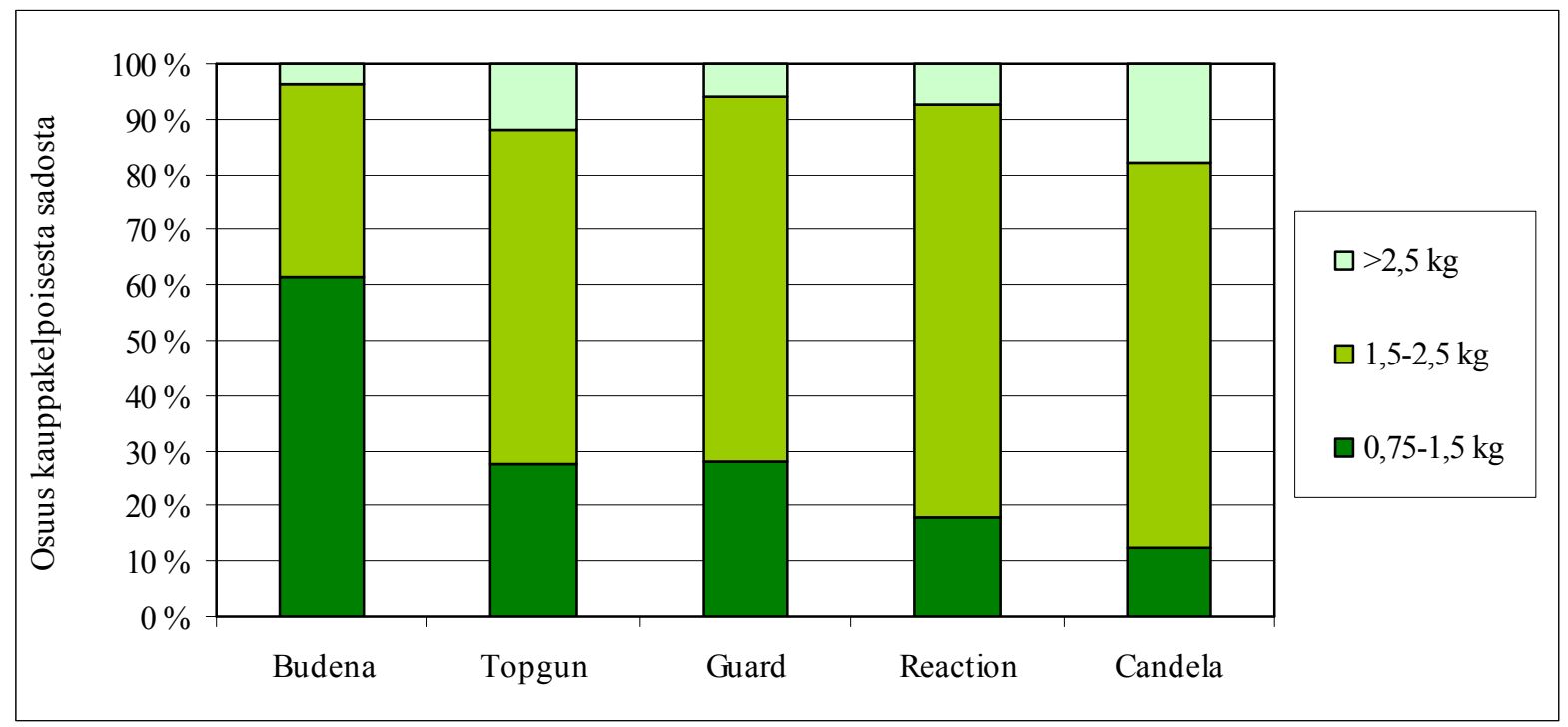

Kuva 1. Varastokeräkaalin koelajikkeiden kauppakelpoisen sadon jakautuminen kerän koon mukaan Mäntyharjun kokeessa vuonna 2006. 


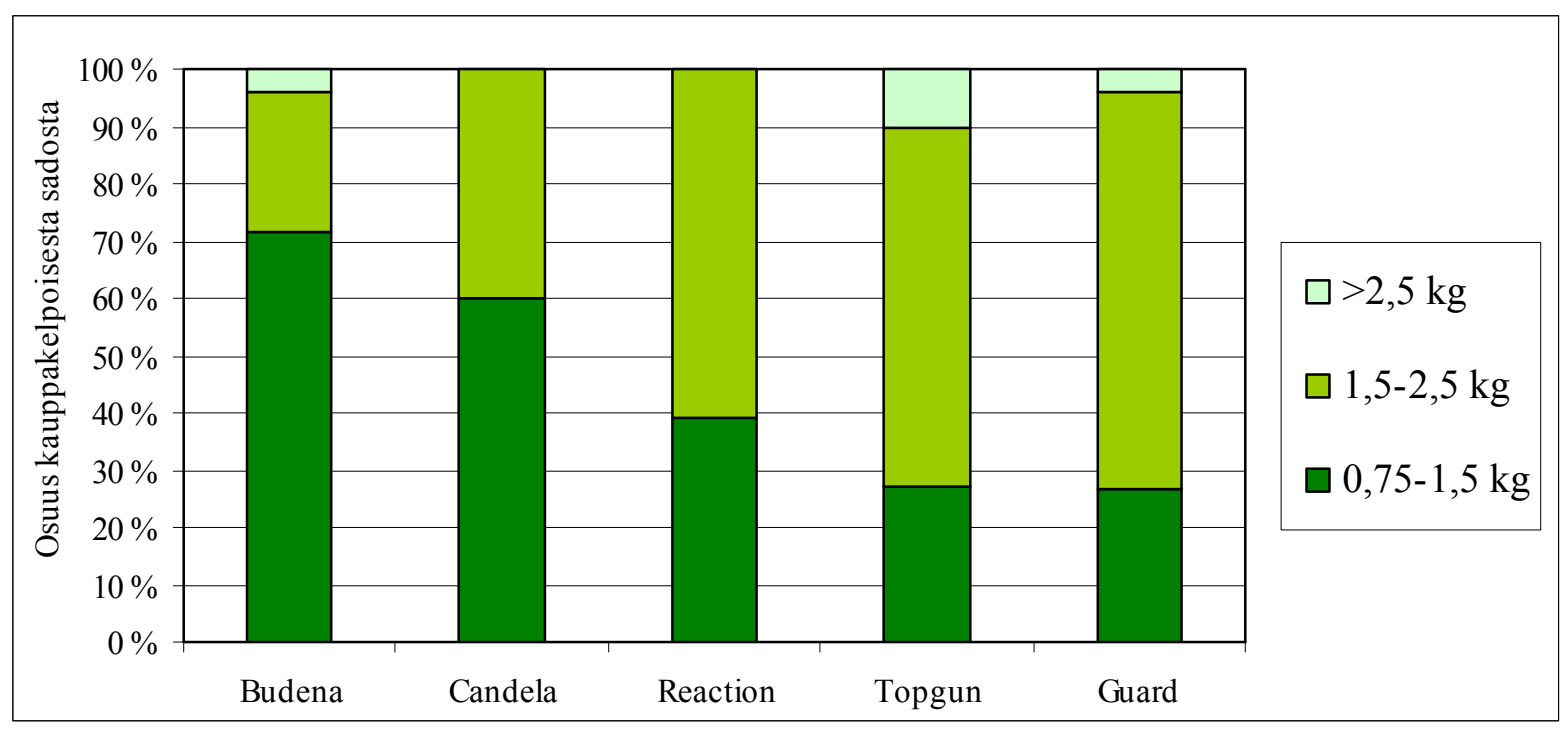

Kuva 2. Varastokeräkaalin koelajikkeiden kauppakelpoisen sadon jakautuminen kerän koon mukaan Nivalan kokeessa vuonna 2006.

Väriltään ja muodoltaan lajikkeet olivat pitkälti toistensa kaltaisia. Reaction-lajikkeen jonkin verran muita tummemman vihreä väri antoi sille parhaan ulkonäön. Kaikkien lajikkeiden tiiveys oli huippuluokkaa eli ne ehtivät hyvin kehittyä valmiiksi kasvukauden aikana. Lajikkeiden kannan korkeus oli 45-50 prosenttia kerän korkeudesta.

Kaalien varastointikokeen ensimmäisessä kauppakunnostuksessa tammikuun lopulla 2007 havaittiin, että koelajikkeista Topgun ja Budena säilyivät varastossa huonommin kuin muut lajikkeet. Sen sijaan muut koelajikkeet olivat säilyneet varastossa Lennox-lajikkeen veroisesti. Maaliskuun kauppakunnostuksessa koelajikkeiden säilyvyydessä oli jo hieman eroja koepaikkojen välillä. Mäntyharjussa Candela- ja Guard-lajikkeet olivat säilyneet varastossa yhtä hyvin kuin Lennox, Reactionlajike hieman näitä heikommin. Sen sijaan Nivalassa Reaction-lajike säilyi jopa hieman paremmin kuin Lennox, mutta Candela-lajikkeen kauppakelpoisuus oli tippunut 75 prosenttiin. Koelajikkeiden kerän keskipaino oli selvästi alhaisempi kuin verranteena olleen Lennox-lajikkeen johtuen koelajikkeiden suuremmasta hehtaarikohtaisesta taimimäärästä sekä osittain myös lajikeominaisuuksista (Taulukko 2.).

Taulukko 2. Varastokeräkaalin koelajikkeiden ja verrannelajikkeen (Lennox) säilyvyys varastossa Mäntyharjun ja Nivalan varastointikokeissa. Päivämäärä kertoo kauppakunnostuspäivän.

\begin{tabular}{|c|c|c|c|c|c|c|}
\hline \multirow[b]{3}{*}{ Lajike } & \multicolumn{3}{|c|}{ Mäntyharju } & \multicolumn{3}{|c|}{ Nivala } \\
\hline & \multicolumn{2}{|c|}{ Kauppakelpoisuus- $\%$} & \multirow{2}{*}{$\frac{\text { Kerän keskipaino }}{\mathrm{kg}}$} & \multicolumn{2}{|c|}{ Kauppakelpoisuus- $\%$} & \multirow{2}{*}{$\frac{\text { Kerän keskipaino }}{\mathrm{kg}}$} \\
\hline & 26.1 .2007 & 21.3 .2007 & & 1.2 .2007 & 22.3 .2007 & \\
\hline Lennox (verranne) & 87 & 77 & 2,4 & 85 & 84 & 1,9 \\
\hline Guard & 84 & 76 & 1,7 & 84 & 82 & 1,4 \\
\hline Topgun & 68 & 59 & 1,4 & 61 & $-*$ & 1,2 \\
\hline Reaction & 87 & 72 & 1,6 & 86 & 86 & 1,3 \\
\hline Budena & 74 & 69 & 1,0 & 73 & $-*$ & 1,0 \\
\hline Candela & 85 & 75 & 1,7 & 86 & 75 & 1,6 \\
\hline
\end{tabular}

* Molemmat varastointierät kauppakunnostettiin 1.2.2007 
Vuoden 2007 kokeessa McCartney-lajikkeen siemen iti hyvin epätasaisesti, joten pellolle istutettu taimimäärä jäi muita koelajikkeita alhaisemmaksi. Attraction-lajikkeen kasvuaika oli noin 100 vrk, joten nostovaiheessa kerät olivat jo hieman ylikypsiä. Myös McCartney-lajikkeen kerät olivat korjuuvaiheessa ylikypsiä, vaikka kasvuaika on sama kuin muillakin koelajikkeilla, 125-130 vrk. Kilatonlajike ei ilmeisesti sovi tiheään istutukseen, koska sen sato jäi muita lajikkeita alhaisemmaksi. Koelajikkeiden satoisuudessa oli suurta vaihtelua. Luteiden vioitukset alensivat kauppakelpoisen sadon määrää kaikilla lajikkeilla. Luteet vioittivat eniten Budena-lajiketta ja vähiten Lennox-lajiketta. Koelajikkeista vain Attraction oli satoisuudeltaan parempi kuin verranteena ollut Lennox-lajike. Edellisenä vuonna kokeessa hyvin pärjännyt Reaction-lajike antoi aika kehnon sadon (Taulukko 3.). Normaalia tiheämmällä istutuksella (38 500 tainta/ha) ei saatu edellisen vuoden kaltaista vaikutusta kerien kokoon. Pienten kerien $(0,75-1,5 \mathrm{~kg})$ osuus kauppakelpoisesta sadosta jäi kaikilla lajikkeilla alle $30 \%$ :in (Kuva 3.).

Taulukko 3. Varastokeräkaalin koelajikkeiden kokonaissato, kauppakelpoinen sato $(\mathrm{kg} / \mathrm{ha})$ ja sadon suhdeluku verrattuna verrannelajikkeeseen sekä sadon kauppakelpoisuus-\% kokonaissadosta kasvukaudella 2007 Nivalassa. Lennox- ja Paradox-lajikkeiden taimitiheys 32000 kpl/ha, muiden lajikkeiden $38500 \mathrm{kpl} / \mathrm{ha}$.

\begin{tabular}{|c|c|c|c|c|}
\hline \multirow[b]{2}{*}{ Lajike } & \multirow{2}{*}{$\begin{array}{c}\begin{array}{c}\text { Kokonaissato } \\
\text { kg/ha }\end{array} \\
\end{array}$} & \multicolumn{2}{|c|}{ Kauppakelpoinen sato } & \multirow{2}{*}{$\begin{array}{c}\begin{array}{c}\text { Kauppakelpoisuus- } \\
\%\end{array} \\
\end{array}$} \\
\hline & & $\mathrm{kg} / \mathrm{ha}$ & suhdeluku & \\
\hline Lennox (verranne) & 68354 & 62838 & 100 & 92 \\
\hline Attraction & 73108 & 69689 & 111 & 95 \\
\hline McCartney & 61607 & 58002 & 92 & 94 \\
\hline Candela & 52966 & 48490 & 77 & 92 \\
\hline Paradox & 51635 & 48223 & 77 & 93 \\
\hline Reaction & 50542 & 45320 & 72 & 90 \\
\hline Kilaton & 45817 & 42025 & 67 & 92 \\
\hline Budena & 39476 & 33321 & 53 & 84 \\
\hline
\end{tabular}



Kuva 3. Varastokeräkaalin koelajikkeiden kauppakelpoisen sadon jakautuminen kerän koon mukaan Nivalan kokeessa vuonna 2007. 
Lajikkeiden värissä ei ollut eroja. Kilaton- ja McCartney-lajikkeilla kerän kiinteys oli hieman alhaisempi kuin muilla lajikkeilla. Lajikkeiden kannan korkeus oli 54-64 \% kerän korkeudesta, pienin Budenalla ja suurin Lennoxilla.

\section{Johtopäätökset}

Tulokset osoittavat, että lajikekoetoiminnassa kaksi kasvukautta on liian lyhyt aika saada aikaan tuloksia, joista voitaisiin vetää pitkälle meneviä johtopäätöksiä. Peräkkäiset kasvukaudet voivat olla hyvin erilaisia sää- ja kasvuolosuhteiltaan, mikä vaikeuttaa tulosten tulkintaa. Kasvukausi 2006 oli keskikesän osalta hyvin kuiva, kun taas kesällä 2007 saatiin runsaasti sadetta. Kesällä 2006 ei tuholaisista ollut suurempaa haittaa, mutta seuraavana kesänä luteet aiheuttivat pahoja vioituksia koekasvustoissa ruiskutuksista huolimatta. Kuitenkin jo yhden kasvukauden tulokset voivat innostaa viljelijää kokeilemaan tilallaan jotain uutta.

Tiheällä istutuksella päästiin joillakin lajikkeilla haluttuun keräkokoon. Vuonna 2006 Nivalan kokeessa Budena- ja Candela-lajikkeiden kauppakelpoisesta sadosta pääosa oli tavoitellussa 0,75-1,5 kg:n kokoluokassa, Mäntyharjussa vain Budena-lajikkeen sato. Vuonna 2007 ei tiheämmällä istutuksella saatu edellisen vuoden kaltaista vaikutusta kerien kokoon, mihin yhtenä syynä voi olla edellisvuotta harvempi istutus. Jotkut lajikkeet eivät myöskään näytä soveltuvan kasvutapansa tai kasvurytminsä vuoksi tiheään istutukseen. Tällainen lajike oli kokeemme perusteella Kilaton.

Varastokeräkaalin lajiketestausten yksi olennainen osa on selvittää uusien lajikkeiden varastointikestävyys. Osa testatuista kaalilajikkeista oli tulostemme mukaan sellaisia, jotka eivät sovellu pitkään varastointiin. Tämä tieto on olennaisen tärkeää etenkin silloin, jos tuotteen markkinointi painottuu pitkälle seuraavaan kevääseen.

\section{Kirjallisuus}

Puutarhayritysrekisteri 2005. Tike. Maa- ja metsätalousministeriön tietopalvelukeskus. Helsinki 2006. ISSN 1456-8268. 